\title{
Touch gesture performed by children under 3 years old when drawing and coloring on a tablet
}

\author{
Lucrezia Crescenzi Lanna $^{\mathrm{a}, *}$, Mariona Grané Oro ${ }^{\mathrm{b}}$

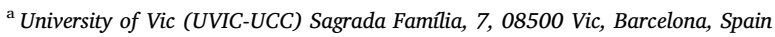 \\ ${ }^{\mathrm{b}}$ University of Barcelona (UB) Pg. Vall d'Hebrón, 177, 08035 Barcelona, Spain
}

\section{A R T I C L E I N F O}

\section{Keywords:}

Touch

Gesture

Young children

Apps

Mobile devices

Interactive design

\begin{abstract}
A B S T R A C T
Children under 3 are enthusiastic users of mobile devices and have the ability to emulate a number of the gestures adults use on touch screens, according to the literature on Child-Computer Interaction (CCI). Nevertheless, relatively few studies have focused on the spontaneous interaction of children with screens. The objective of this empirical research is to study unstructured interactions of children under 3 with two apps that permit free drawing and coloring. Observation includes the first gesture used for interaction and the use of onscreen tools (e.g. color palette). Twenty-one participants aged 14 to 33 months (average of 24 months) were recorded playing with free drawing and coloring apps on a tablet using a non-invasive method in a natural context (two nursery schools, one in London and one in Barcelona). Analysis of the data gathered showed that children under 3 adapt their gestures to the content of the apps and suggests that the use of tools may begin from 24 months. Based on those results, the content of an additional 32 apps for drawing and coloring aimed at children from zero, one or two years old were then reviewed. The analysis highlighted the need for more studies on the interaction of young children with apps to foster the development of interactive resources appropriate to a child's age and development.
\end{abstract}

\section{Introduction}

Studies that focus on the pairing of children and screens have been undergoing a revolution since the first mobile tablets with touch screens appeared in 2010. Before that, researchers focused on the relationship between children and screens by concentrating on exposure to television and other audio-visual resources (Greenfield and BeaglesRoos, 1988; Schmidt et al., 2008). Studies on the effects of television consumption have identified problems related to young children's passive exposure in front of the screen, a position actively maintained by the AAP (American Academy of Pediatrics, 1999; 2011), but in contrast to other research in areas such as attention development and learning (Kirkorian et al., 2008).

On the other hand, research on the interaction between children and computers actually began with the work of Papert in the $80 \mathrm{~s}$ and early $90 \mathrm{~s}$, as indicated in the historical analysis on the origins of ChildComputer Interaction (CCI) by Read and Bekker (2011), Resnick (1991) and Ackermann (1991) developed the first studies in the field; likewise the research of Druin and Solomon (1996) shifted the focus on to how the children themselves evaluated the programs, resulting in a clear shift toward the study of the interaction between the child and the technology, and promoting the idea that children could participate in the design of products targeted at them.

Research on CCI, as summarized by Hourcade (2008), has been focused on observation along with interviews with those who act as "testers" of computer programs (evaluating products that the developers design for children); as "informers" in interview sessions (with the aim of learning more about the ideas and interests of younger children); as well as "participants" in the design itself. One extensive study on the role of developmentally diverse children and the different types of contributions that they have made in product design based on User-Centered Design (UCD) methodology was carried out by Börjesson et al. (2015) and included an analysis of 325 articles on CCI, of which only 88 considered the participation of children (between 6 and 12 years old) in the design process of digital products for children. This perspective is in line with the findings of a previous study by Bruckman, Bandlow and Forte (2009) on the essential role of children in the design process of technology for children.

Since 2010 the diffusion of smartphones and tablets has resulted in an increased number of studies in the field of Child-Computer Interaction, although research on the development of the interaction between children and technology is still in its infancy. The challenge

\footnotetext{
* Corresponding author.

E-mail addresses: lucrezia.crescenzi@uvic.cat (L. Crescenzi Lanna), mgrane@ub.edu (M. Grané Oro).
} 
inherent in the study of CCI is not only to distinguish between the characteristics of interaction design for adults and that of children from the age of 6 (Vatavu, Cramariuc and Schipor, 2015), but to take into account the differences between even the youngest users in a more developmental sense, studying the features of interaction design needed to suit a child's age and rapid changes in development.

In the field of CCI, research on interaction design is generally carried out from one of two common approaches: an analysis (based on design principles) of the product, or a study of the users that interact with the products (centered on the user). The first is based on the heuristic method for usability analysis developed by Nielsen and Molich (1990), in which usability experts are questioned with regard to all of the design aspects of a system (whether it is a web page, a videogame, an application, etc.). In a similar manner, over the years the model has been systematized into different evaluative processes for digital systems, originating from interaction design principles as well as the judgement and knowledge of experts in the field. From an educational perspective, various authors have performed analyses of the resources available for children with the objective of determining their quality and suitability for children, not only from a usability and design perspective (Rockman, 2010; Watlington, 2011); but also with regard to the educational potential of the applications (Shuler, 2009; Goodwin and Highfield, 2012); with a view to their appropriateness for the cognitive development of the child (Guernsey, 2013); as well as a focus on perception, attention and the limitations of memory (Yee et al., 2012). Recently, a study of the interaction design of 100 tablet and smartphone apps for children under 8 was carried out by Crescenzi and Grané (2016), allowing for the study of interactive resources while taking into account a child's development and its implications in the area of visual design, interactive systems, organization and navigation, mental models and cultural references, accessibility, legibility and sound.

However, the paradigm for the study of interaction design that Nielsen defended for years has also evolved into an approach that is centered on the user and his or her experiences with the digital content (Norman, 2003). Read and Bekker also refer to Child-Computer Interaction as the "study of the activities, behaviors, concerns and abilities of children as they interact with computer technologies" (2011, pg. 7), putting a clear emphasis on the action of the child and not on the technological resources. Thus, the second methodological paradigm in the study of CCI is found in the observation of the child's interaction with devices, games, programs, and apps with the aim of studying interactive gestures from the age of 2 (Abdul-Aziz, 2013), interaction as part of the process of development and learning in toddlers (Kirkorian and Pempek, 2013), as well as perception and comprehension (Nacher et al., 2014). Hanna et al. (1997) had already developed guidelines for carrying out usability tests with children divided into three age groups, 2-5 years old, 6-10 years old, and 11-14 years old. These guidelines are based on the previous work of Druin and Solomon (1996) and Dumas and Redish (1993), although the latter referred to adult participants, not children. Years later Bruckman, Bandlow and Forte (2009) proposed different methodologies for the design and evaluation of digital content for children between 2 and 14 years old that went beyond traditional usability testing and employed cooperative investigation, including the promotion of thinking out loud, the verbalization of one's own actions, interviews after use, collaborative discovery and peer-mentoring.

An alternative to the direct observation of a child's interaction with a screen can be found in surveys of parents and educators about what children do with technology and how they use it. Recently Marsh et al. (2015) and Wen and Zainon (2015) combined different methods by observing the interaction of children with tactile and mobile devices, in addition to complementing that data with parents' knowledge gained through interviews, while also taking into consideration the mental models of the users that designers utilize in the process of creating the digital content. In any case, the perceptions of parents and educators often differ from the reality of the situation as shown by Ahearne et al. (2015). After questioning 82 parents they reached the conclusion that children under 2 could interact with tactile screens without difficulty and that they demonstrated a broad range of abilities in doing so. However, this conclusion was not corroborated by more detailed studies on the ability of very young children to use tactile devices, as will be seen later in this article.

\section{Related works}

The digital content industry is creating more interactive content for children than ever before (in the Apple Store alone there are more than 80,000 apps for children). The constant search of both parents and educators for resources that allow for learning, play, and entertainment (Troseth et al., 2016) drives the production of content designed for children and inundates the market. However, not all children use these apps under the supervision of their parents. A survey of 2,000 parents and caregivers in the UK (Marsh et al., 2015) shows that children (28\% of those under 1 and up to $40 \%$ of those under 5) typically use tablets on their own during the week. For this reason, and as recommended by Read and Markopoulos (2013), it is ever more important to improve the design of interactive content for children and provide a well-founded description of best practices for the promotion of children's interaction with technology.

When compared with traditional media, the literature shows that the use of interactive technology (including computers and touch screens in general) with preschool-aged children promotes learning in a more significant way than passive exposure to on-screen audiovisual content. Lauricella et al. (2010) demonstrated this in an investigation in which computer videogames were used with a sample of 72 children aged between $2 \frac{1}{2}$ to 3 years old. Similarly, a study by Kirkorian and Pempek (2013) showed how children between 2 and 3 years old reacted with more ease and learned more rapidly in front of screens that encouraged them to interact than children placed in front of a television. Within the school setting, various international studies on the use of Information and Communication Technologies (ICT) in preschool-aged children point to a positive relationship with regard to digital interaction in the learning process, as suggested by a recent experience involving the introduction of an iPad in a nursery school in England with children from the age of 3 (Flewitt, Kucirkova and Messer, 2014). As shown in other research, children that use computers at an early age exhibit better problem-solving skills when compared to children that do not use technology (Clements and Samara, 2003; Vernadakis et al., 2005).

Accepting the premise that digital content for children must be comprehensible to the user at which it is aimed in order to promote learning, research in the field of CCI has focused on the suitability of technology designed for preschool-aged children by studying children's comprehension of the content. Nacher et al., (2014) studied the comprehension of visual and animated instructions in children under 38 months old. McKnight and Fitton (2010) focused on children's understanding of verbal and visual instructions and their effects on activities involving ICT. Couse and Chen (2010), with a sample of 41 boys and girls between 2 and 6 years old, were able to show how the children learned to use the interfaces of touch screens and how they could even become autonomous users of the technology, exploiting it as a tool for the expression and representation of their ideas. The evolution of technologies from the computer to the touch screen has marked a change in the interaction of children with these devices, eliminating the need for a mouse or keys and substituting physical buttons with what Abdul-Aziz (2013) calls "soft buttons" . Early exposure to mobile devices on the part of children as young as 12 months old has motivated researchers to undertake new studies on the gestures that a child makes when interacting with a touch screen in order to compare them with the ones that are actually necessary in order to use apps, as Abdul-Aziz makes clear that apps "need to be age-and-gesture-appropriate to be 
effective" (2013, pg. 447). As shown by McKnight and Fitton (2010), there is a discrepancy between the gestures the developers require in the content they design, and the comprehension displayed by and actions of children aged 6-7 who are not able to understand those instructions and carry out the interactions required. This is in large part due to the terminology used to describe the gestures. In a similar vein, Hiniker et al. (2015) found that children under 3 years old are only able to understand instructions when they come from an adult, and that they do not comprehend verbal or audiovisual instructions when they come from the screen or device; although just slightly later, from about $31 / 2$ years old, children can more easily understand them and carry out the actions indicated by the content.

In an analysis of the interaction design of 100 apps designed for children under 8 years old (Crescenzi and Grané, 2016), the gestures classified as "necessary for interaction" in one or more apps from the sample included: tap, double tap, press (longer duration), draw a straight line (in a single stroke), horizontal scroll (touch and hold to move horizontally), vertical scroll (touch and hold to move vertically), circular gesture, drag - (time and distance), scrape, swipe, rotate, use of more than one finger, use of both hands, reduce and enlarge with two fingers, and pinch.

Nevertheless, observational research on the gestures that children use from the age of 2 shows that in reality a much more restricted range of gestures are displayed, as summarized in the table below, suggesting that there is a contradiction between the content on offer in the market and the cognitive and motor abilities of the target users, as previously observed by Vatavu, Cramariuc and Schipor, (2015). Likewise, some of the investigations demonstrated that children use gestures that are not included at all in the interaction design of the apps studied, banging (touching the screen with the whole hand) being one example.

Researchers have operated from a wide range of paradigms in the study of the interaction of children under 3 with touch screens (education, psychology, and technology).

Abdul-Aziz (2013) set out to study the actions that children between 2 and 12 years old were capable of performing on touch screens and observed a total of 33 participants. From the age of 4 the children were able to make all of the gestures included in the study (tap, drag/slide, free rotate, drag \& drop, pinch, spread and flick) with the touch screen, but children under 3 were not able to do pinch or spread, and those under 2 could not perform drag \& drop, rotate, or spread. The study established a relationship between children's ages and each of the gestures.

A recent study in France by Cristia and Seidl (2015) recorded the responses of 453 families with children between 5 and 40 months to ascertain the average usage of touch screens by small children and confirmed that use is continually on the rise, including with children under 3 , showing that $78 \%$ of the children used them to view photos, $68 \%$ to watch videos, and $50 \%$ to play with apps. Participants were also asked about the activities performed on the screens and the gestures that the children use when interacting with them and, according to parents, tap was used by $71 \%$ of the children, flick by $68 \%$, press and drag by $41 \%$ and press by $36 \%$. To a lesser extent gestures such as banging on the screen, swipe, pinch, and spread were seen. The authors of the study confirmed that there is a progression in the gestures used by children that correlates with age (Cristia and Seidl, 2015), and that this also takes place in children under 3, according to parents (Marsh et al., 2015).

Finally, Nacher et al. (2015) carried out an experimental study with 32 children between 24 and 38 months old with the objective of identifying the gestures that children under 3 can use when interacting with apps and how those gestures are learned. They studied the time dedicated to and the success that children had with gestures such as tap, double tap, long press, drag, scale up, scale down, one-finger rotation, and two-finger rotation, as well as which of those gestures were used in a sample of 100 different apps. The gestures the participants found most complicated to perform were double tap, long press, and two-finger rotation. However, they also observed that children between 2 and 3 years old were able to learn and consolidate new gestures if the applications required them to, without exerting too much of an effort.

\section{Empirical research}

\subsection{Objectives}

The aim of this study is to provide evidence on how children under 3 interact with touch screens.

In contrast to previous studies, the focus is on unstructured interaction and the gestures that the child performs on the screen without assistance or a prior introduction to the features of the app, and also without the interference of instructions, goals to accomplish, or time limits. While it has already been demonstrated from a psychomotor perspective that preschool-aged children are capable of imitating some gestures, little is known about the gestures that children are capable of using spontaneously to both begin and continue the process of interaction with apps.

Individual interaction with a tablet's touch screen will be observed in a context that is familiar to the participants (at their nursery school, during school hours) in order to study the gestures that the children are capable of using spontaneously to both begin and continue the interaction with apps. For example, the use of a palette of colors for fingerpainting is a familiar action for children in this age range, as confirmed by educators, but children did not have access to computers, tablets or smartphones in both nursery schools participating in the study. The movement used to transfer this action to the tablet's screen requires the use of a simple gesture such as tap (seen in children under 1 year old). Nevertheless, there is a gap in our understanding as to whether children under 3 use tools for coloring and drawing. The interaction design of content for children should take into account this natural relationship between children and technology, in addition to a consideration of the development of preschool-aged children in order to improve design quality in the creation of apps, in particular their accessibility and usability, as part of their overall suitability for the target user.

The specific objective of this paper is to explore the interaction of children under 3 with two creativity-focused apps. One app will allow them to draw freely on a blank white page while their spontaneous gestures are studied, while the other will give them the opportunity to color in a figure in order to observe differences in the gestures used, as well as in the use of tools. The two applications were chosen because the activities are familiar to the children, given their previous experience finger-painting on paper.

The following questions have been formulated with reference to the first gestures used, the use of tools present on the screen, and the age factor in the coloring and drawing activity:

- RQ1. How do children under 3 initiate interaction when presented with a white screen and a figure/outline to color?

- RQ2. Do the gestures used during these activities change according to the age of the child?

- RQ3. Does the interaction change depending on the content presented on the screen?

- RQ4. At what age do children begin to make intentional use of tools for drawing and coloring?

Based on the results of the observation of the children's interaction with two selected apps, and in order to establish whether similar apps adapt to the user, the content of 32 additional apps for drawing and coloring targeted at children under 3 will be analyzed in the second part of the study, leading to another research question:

- RQ5. Do the design elements in the sample of apps suit the characteristics of the user? 
This combination of methodologies (observational study and apps review) is also employed in previous research by Abdul-Aziz (2013) and Nacher et al. (2015), as shown in Table 1.

\subsection{Material and methods}

The research presents a mixed sequential design, following a pragmatic paradigm composed of two studies: in the first, 21 children between 14 and 33 months interacted with two tablet apps. The data obtained from this first study led the same team to carry out an analysis of the interaction design of 32 apps for drawing and coloring in March of 2016, directed at children under 3 years old. This second part of the research is presented in Section 4.4 (Analysis of Apps for Children).

\subsection{Observing children's Interaction: study design}

The primary objective of the first part of the study is to observe the interaction of preschool-aged children with an iPad touch screen. An empirical method of observation was used and the research was carried out in a natural context (a nursery school during school hours) by means of a non-invasive technique that is summarized in the following paragraphs, as well as being available in more detail in a previous article (Crescenzi, 2013).

Each participant was recorded while they interacted with a tablet touch screen as part of a free drawing or coloring activity. Next, a content analysis technique (video) was used to encode specific observations of the recorded interaction.

Each child was offered the opportunity to draw and color on the screen of the tablet individually. To reduce the risk of bias, the two stimuli were presented in alternating order for each subject (first the drawing app and later the coloring app, or vice versa). No initial instructions were given apart from the question, "Do you want to try it?" while offering the tablet. Children were allowed to choose whether they wanted to participate and they were told they could stop at any point. All children began in the same position, with the iPad's placement and the child's distance from the screen controlled. The lighting in the room was also controlled. The subject was allowed to determine the length of each activity, as well as when to begin and end interaction with the tablet. Two boys aged 27 and 36 months participated in the pilot test carried out in a nursery in London. Both performed the activities and no major alteration of procedure or materials were necessary.

Two researchers were responsible for compiling the data after they had spent a few days becoming acquainted with all of the children in the classroom. The sessions were carried out by the same two researchers and one child at a time in one corner of the classroom, while the rest of the class (between 6 and 12 children, depending of the day) was on the patio or on the other side of the space, engaged in other play activities with two teachers.

\subsubsection{Ethical issues}

There are potential ethical implications associated with two aspects of the study: the participation of children under 3 years old, and the type of data collected (audio-video recordings). In light of this, informed, written consent was required of the families of the participants. An information sheet was provided before the observation that included the objectives of the study, the projected duration, the type of participation sought from the children, the procedure, the confidentiality policy, etc. Particular attention was paid to the way that the forms were distributed in the nursery schools in both London and Barcelona, taking into account issues related to cultural and intercultural sensitivity. With regard to the methods employed in the data collection, including the video recording, an additional, specific consent form was required from the parents authorizing the use of audio and video recording and still images, including their use in the data analysis, potential use in presentations at conferences, inclusion in scientific articles, and other types of diffusion of the study results (e.g., the researchers' web page). 


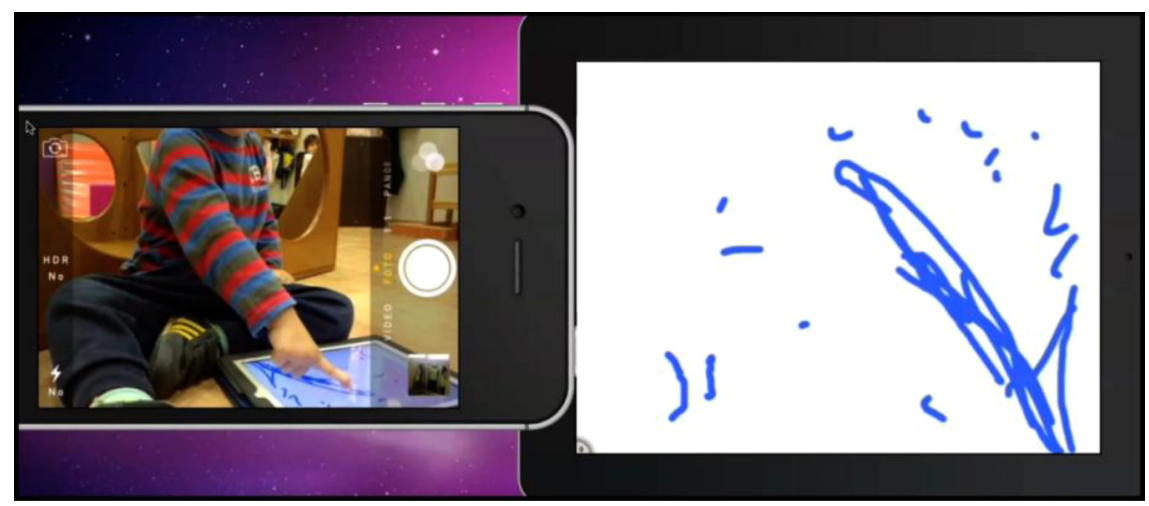

Fig. 1. Screenshot from the computer. The child's action is seen on the left, while the screen of the app "Dessine Moi (Akrio)" on the right shows the simultaneous results of the child's actions.

\subsection{Materials}

The observational study involved the use of a non-invasive data collection method that made it possible to record the child's activity from different points of view for a detailed, multimodal analysis of their interaction with the screen. Data collection was performed in two stages. The first was in July 2013 in a nursery school in London by means of a technique described in detail in two previous publications (Crescenzi 2013; Crescenzi et al., 2014), and the second took place in a nursery school in Barcelona in May 2014. An improved data collection technique for audiovisual material was used in Barcelona that allowed for a reduction of the number of devices used (from 7 to 4), as well as eliminating the need to edit the videos after the fact in order to synchronize them. This improvement facilitated the data collection process without affecting the quality of the audiovisual information or the process of coding the data, which remained unchanged.

Specifically, three mobile devices (two tablets and one smartphone) and one computer were used in the following manner:

- The children performed the free drawing and coloring using a tablet (iPad) and the apps "Coloring Zoo (RR)" (finger-painting using a picture of a cat) and "Dessine Moi (Akrio)" (blank screen and a digital paint palette). Both apps used a restricted range of colors and offered multi-touch capabilities, with only a small number of interactive screen elements.

- Another tablet and a smartphone (iPhone) on a small tripod were used as video cameras. The researchers did not need to record the videos on the memory of the respective devices, instead the camera was activated and the option for AirPlay Mirroring was selected. The video was then wirelessly cast onto the computer screen using the Reflector software installed on the computer. Figs. 1 and 2 show the smartphone and the tablet as a child uses them to draw and color.

- The screens of the three mobile devices were simultaneously cast to the computer screen and QuickTime software allowed for screen recording, thus eliminating the need to synchronize the video content later (the screens of the devices along with the recordings of the children while they were interacting with them). A screenshot of the two streams simultaneously recorded on the computer is shown in Fig. 3.

\subsection{Coding interaction}

The videos of the participants' free drawing and coloring was coded with a multimodal method (observing gestures, movement, and action on the screen). The data, however, were reviewed later by means of a structured observation and a statistical analysis with SPSS. This required the creation of three observation files in an Excel spreadsheet and a codebook for each of them. The codes of the three files are detailed below.

- The categories in the first file focus on touching gestures used by the children to begin their interaction with the screen in the two activities presented. Observations included whether the child studied the screen before touching it deliberately, the type of gesture, ${ }^{1}$ and the use of two hands or more than one finger during the interaction.

- The second file recorded aspects relevant to the use of tools on the iPad (color palette, eraser, brushes, etc.). In addition to observations on the types of gestures and the use of hands or fingers to draw or color intentionally, attention was also placed on the type of tool used by the children and the number of touches on the tools.

- The third file allowed for a detailed recording of the interaction during the coloring process in order to detail any intentional use of the color palette. The object or the section of the object being deliberately colored was also observed (to the extent that the beginning and ending of the stroke was within approximately $1 \mathrm{~cm}$ of the margins of the figure) as well as the number of strokes made on the same point or area of the figure.

\subsection{Participants}

Study participants were contacted through the directors of the schools, as well as parents (or other caregivers), and included children with typical development who were all in the same class in the nursery school in either London or Barcelona. Inclusion criteria included: the children's age, up to 36 months, and the signing of a consent form by the families.

In the end 27 typically developing children (i.e., no visual/physical impairments) between 14 and 36 months took part in the study. Two of the boys (aged 27 and 36 months, respectively) participated in the pilot test, while one girl (24 months) and one boy ( 23 months) did not want to play with the tablet. Additionally, technical problems with the recording equipment did not allow for the recording or analysis of two other boys (aged 26 and 35 months).

As summarized in Table 2, the interactions of 21 participants aged 14 to 33 months (five aged between 14-19 months; five between 20 and 23 months; seven aged 24-27 months and four aged between 28-33 months) with the tablet's apps for both free drawing and coloring were recorded and analyzed.

It was not possible to clearly identify the way that results may have been influenced by a child's familiarity with the device, although an initial questionnaire was sent to all of the parents to ascertain the children's previous experience with tablets and creativity apps. The questionnaire for parents/caregivers included a section on personal

\footnotetext{
${ }^{1}$ Tap; press; stroke (tracing a line over $1 \mathrm{~cm}$ long); circular stroke; horizontal scroll; vertical scroll; drag; scrape; flick; reduce-enlarge with two fingers.
} 


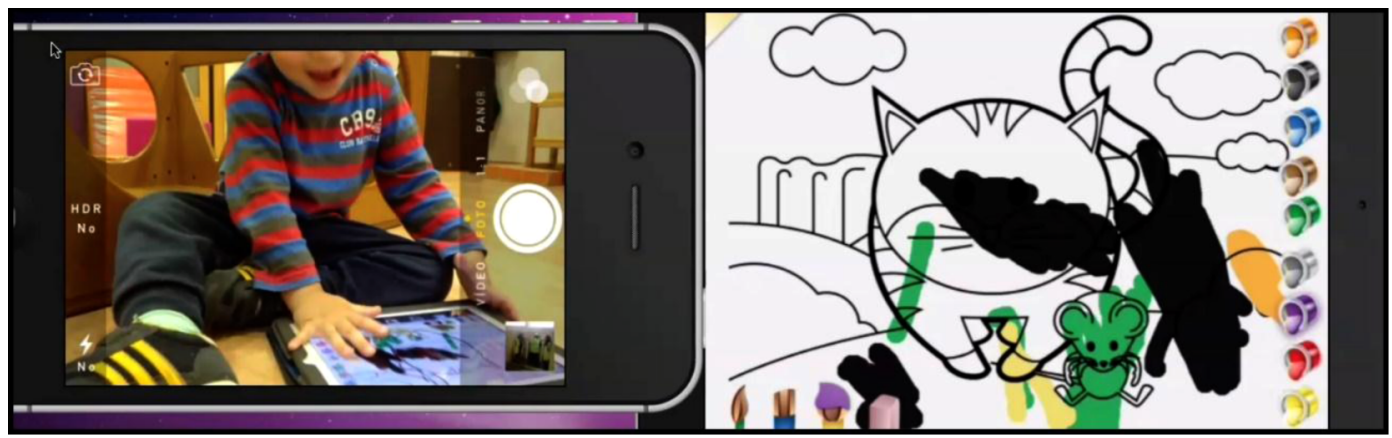

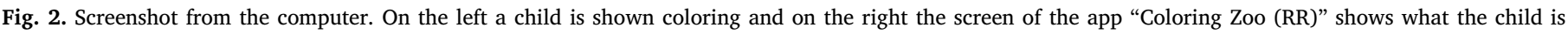
completing at the same moment.

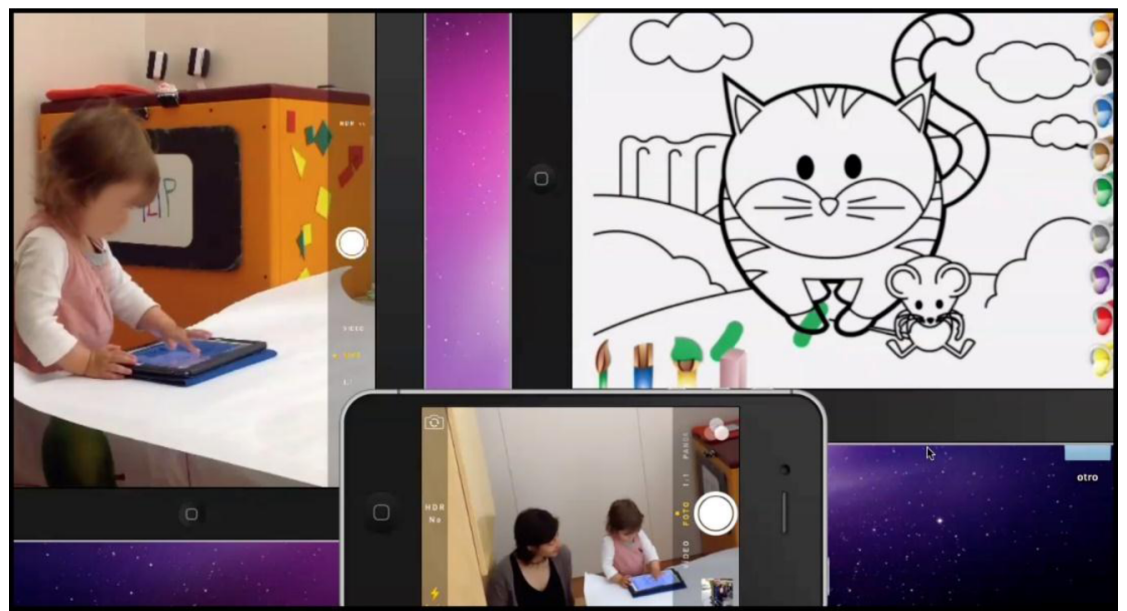

Fig. 3. Screenshot of the video recorder showing real-time reproduction, on the computer, of the three screens of the mobile devices used in the study.

Table 2

Sample of girls and boys participating in the study.

\begin{tabular}{lllll}
\hline & \multicolumn{2}{l}{ Kindergarten } \\
& Barcelona & London & \\
\hline \multirow{2}{*}{ Sex } & F & 6 & 5 & Total \\
& M & 3 & 7 & 10 Boys (average 21 months old) \\
Total & 9 & 12 & 21 & \\
\hline
\end{tabular}

details and a Likert scale survey (22 items) about family habits related to technology, as well as items related to the child's habits, practice and familiarity with technology, such as touch screen and handheld devices. No parent indicated that their child had previously used the apps associated with the study. The majority of the parents $(79 \%)$ stated that their children had not previously played with touch screen devices or that they had done so very occasionally, in contradiction with the available data on the use of smartphones and tablets in early childhood that show $72 \%$ of children over 2 years old use a mobile device regularly, while the same occurs with $38 \%$ of children under 2 (Rideout, 2011). This tendency could be attributed to the debate of the use of ICT in early childhood, generating responses that some parents believe are more socially acceptable or appropriate.

In the results no correlation was found with the sex or background of the participants, which is consistent with the study by Nacher et al. (2015); however, the number of participants (sample size) may be insufficient for determining the influence of these variables in the development or behavior of the participants. Differences with reference to age are outlined below along with the results of the study.

\section{Results}

Presented below are the results of the observations of the participating children interacting with the two creativity apps, followed by the main findings of the analysis of the interaction design in the sample of drawing and/or coloring apps.

\subsection{First touch}

A total of 40 cases related to a child's first interaction with an app were coded: 21 with a white screen for drawing, and 19 with the app containing the cat to color, since two children ( 23 and 24 months) did not touch the screen at any time to color in the figure of the cat. All of the children studied the screens before touching them.

In the analysis the screen was separated into 9 zones when viewed from a horizontal position (the initial orientation of the tablet when presented to the children), as seen in Figs. 4 and 5.

In the majority of the cases the interactions started in the central area of the screen. In total, $72 \%$ of the first interactions during the drawing activity were made in the central zones $\mathrm{A}, \mathrm{H}$, or $\mathrm{F}$, while $63 \%$ of the first touches for coloring occurred in zone A (the cat's face). In the coloring activity, apart from zone A, the interactions sometimes began where the tools were located (in color, as opposed to the drawing activity where they were in black and white). However, as detailed in the following Section (4.2), two boys and two girls (from 19 to 24 months) who initially touched zone G, containing the tools, did not intentionally use the tools at any time.

These results concur to some extent with visual design analyses regarding universal design principles on screen composition. For 


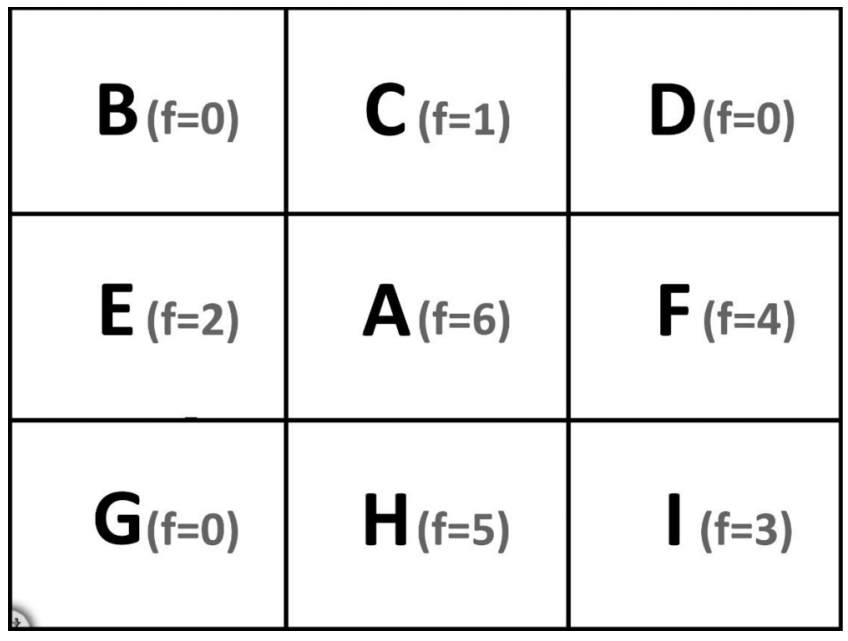

Fig. 4. Screen zones for the app "Dessine Moi (Akrio)" including the number of first touches made by study participants when beginning the drawing activity on the white screen.

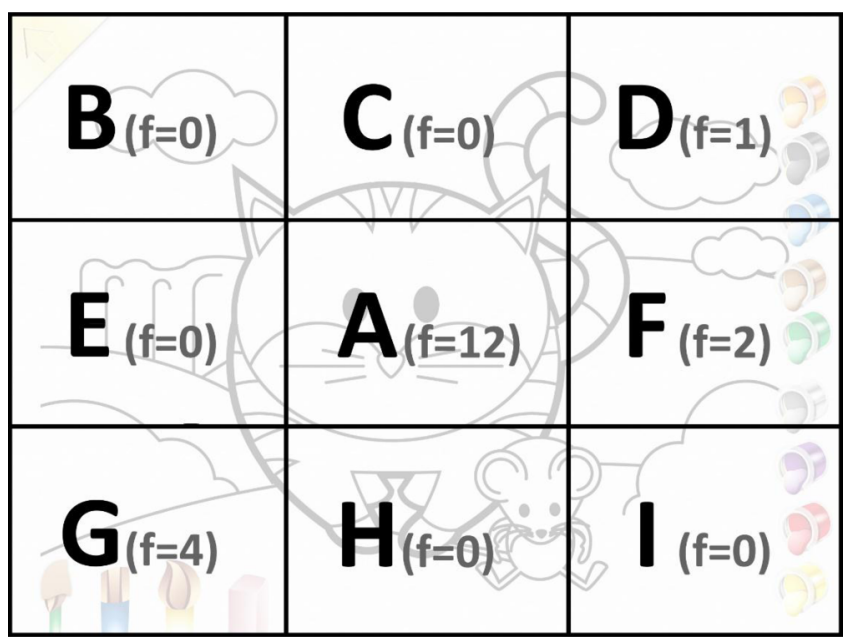

Fig. 5. Screen zones for the app "Coloring Zoo (RR)" including the number of first touches made by study participants when beginning the coloring activity.

Dondis (1974), composition is the most important step in human visual reference and is the balance that allows for correct visual perception. In accordance with the ideas of Edmund Arnold in the $1950 \mathrm{~s}$ on the Gutenberg Diagram, the central and lower-right zones are "strong zones" for the user's visual attention (Butler, Holden, and Lidwell, 2003). Although this concept is more applicable to printed and textual materials, from an interaction design perspective it does meet the "Golden Grid Rule" that is applied to photographic composition (Goldstein, 1997).

The results seen for under $3 \mathrm{~s}$, who initially focus their attention on the central zone or to the lower-right, coincide with what experts in graphic design recommend and are supported by references to visual perception in adult psychology. The data indicate that the pattern is reproduced and that children have a tendency to begin interacting from the central zone of the screen for free drawing, and for coloring as well. The weak zones for visual attention are situated in the upper portion of the screen (B, C, and D), the same zones where attention is focused for reading and writing. In contrast, the central and lower zones are where children under 3 usually begin their spontaneous interaction.

Children generally used their index finger to start interacting with the device, although there were some exceptions. Two girls (25 and 32 months) began both activities with their thumb and middle finger, respectively. Three children (one aged 16 months and two aged 23 months) made their first stroke by touching the screen with more than one finger. Finally, one 17 month old girl started by using her whole hand to stroke the screen. Given these differences, it may be important for applications directed at children under 3 to support multi-touch interaction to adapt to different types of interaction. We observed that during the coloring and drawing activities six children (aged 17, 18, 19, 23, 25 and 32 months) touched the screen with different levels of pressure and finger/s (or hands, alternate or at the same time, and sometimes with a fingernail or the back of the hand), as such adjustment of the screen's tactile sensitivity (touch screen booster) to adapt it to different types of interaction may be a means of supporting the interaction of very young children with creativity apps. The participants performed the activities using only the right hand ( $f=10,77 \%$ ), only the left hand ( $\mathrm{f}=3,14 \%$ ) or in five cases $(24 \%)$ alternated hands (although four children used the right hand more and one used the left more). Exclusively three children (18, 20 and 30 months) varied their behavior with the activity: alternating between two hands with one app (although mostly favoring the right) while for the other app they had a preference for using their right hand, but a pattern was not found, as two children alternated hands for coloring and one did so for drawing. More study, with a larger sample and stratification by age would be necessary to clearly identify the multiple ways that children of this age experiment with touch screen interaction.

Finally, the observation showed that children began their interactions with the two apps using the same finger (although one 20 monthold boy touched the cat with his index finger for coloring and used both of his hands to touch the white screen for drawing); however, 8 children (of the 19 that took part in the two activities) changed the type of gesture they made depending on the content on the screen: they made a stroke (tracing a line of more than $1 \mathrm{~cm}$ ) to begin coloring, and a tap-in one case a boy pressed (longer)—to begin drawing. As seen in Table 3 , the content presented on the screen appears to produce a different gesture in children under 3 years old. While children of all ages almost exclusively employed the stroke gesture to start interaction with the coloring app, they also used other gestures (press before 20 months and tap mostly after 24 months) to start the drawing activity.

\subsection{Painting tools}

Two-thirds of the sample did not intentionally touch any of the tools during the activities (all eight children 23 months and younger, one 23month-old girl, three children 2 years old and two girls, aged 25 and 28 months). A touch is coded as unintentional when a child appears to touch accidentally, without looking at the screen or with a part of the hand the child is not using to interact with the app. Only seven children between 23 and 33 months (see Table 4), used the color palette at any moment. Two of them (a 30-month-old boy and a 26-month-old girl) used the brush and eraser during the coloring activity with the tablet,

Table 3

Gestures employed for starting interaction with drawing or coloring apps.

\begin{tabular}{llllll}
\hline & Age group & N & Tap & Press & Stroke \\
\hline \multirow{2}{*}{ Drawing } & $14-19$ months & 5 & 1 & 3 & 1 \\
& $20-23$ months & 5 & 1 & 0 & 4 \\
& $24-27$ months & 7 & 2 & 0 & 5 \\
& $28-33$ months & 4 & 3 & 0 & 1 \\
& Total & $\mathbf{2 1}$ & $\mathbf{7}(\mathbf{3 3 . 3} \%)$ & $\mathbf{3}(\mathbf{1 4 . 3 \% )}$ & $\mathbf{1 1}(\mathbf{5 2 . 4 \% )}$ \\
& $14-19$ months & 4 & 0 & 0 & 4 \\
& 20-23 months & 5 & 0 & 0 & 5 \\
& $24-27$ months & 7 & 0 & 0 & 7 \\
& $28-33$ months & 3 & 2 & 0 & 1 \\
& Total & $\mathbf{1 9}$ & $\mathbf{2 ( 1 0 . 5 \% )}$ & $\mathbf{0}$ & $\mathbf{1 7}(\mathbf{8 9 . 5 \% )}$ \\
\hline
\end{tabular}


Table 4

Interaction of the 7 children (identified by age and sex) that intentionally touched the color palette and/or other tools at least one time.

\begin{tabular}{|c|c|c|c|c|c|c|c|c|}
\hline & & 33-girl & 32-girl & 30-boy & 27-girl & 26-girl & 25-boy & 23-boy \\
\hline \multirow[t]{2}{*}{ Color palette } & Once & & & $\mathrm{x}$ & $\mathrm{x}$ & $\mathrm{x}$ & & \\
\hline & More than once & $\mathrm{x}$ & $\mathrm{x}$ & $\mathrm{x}$ & & & $\mathrm{x}$ & $\mathrm{x}$ \\
\hline \multirow[t]{2}{*}{ Others tools } & Once & & & & & $\mathrm{x}$ & & \\
\hline & More than once & & & $\mathrm{x}$ & & & & \\
\hline
\end{tabular}

Table 5

Time spent drawing and coloring for each age group.

\begin{tabular}{lllll}
\hline & Age group & N & Maximum & Average \\
\hline \multirow{2}{*}{ Drawing } & $14-19$ months & 5 & $1: 25: 59$ & $0: 27: 59$ \\
& $20-23$ months & 5 & $2: 27: 00$ & $1: 06: 24$ \\
& $24-27$ months & 7 & $1: 38: 59$ & $0: 33: 51$ \\
Coloring & 28-33 months & 4 & $1: 22: 00$ & $0: 54: 00$ \\
& $14-19$ months & 4 & $0: 25: 59$ & $0: 19: 14$ \\
& $20-23$ months & 5 & $0: 57: 59$ & $0: 29: 48$ \\
& $24-27$ months & 7 & $2: 30: 00$ & $1: 16: 25$ \\
& $28-33$ months & 3 & $1: 52: 00$ & $1: 28: 00$ \\
\hline
\end{tabular}

although the girl only touched both tools one time and the older boy only used the eraser, but not the brush.

This data indicates that the use of those instruments (brushes or erasers, and the color palette, in under $2 \mathrm{~s}$ ) does not appear to be appropriate for the age group of the study.

A total of 25 uses of the color palette or other tools for drawing and painting were recorded. Each child inspected the screen for at least $3 \mathrm{sec}$; in 5 cases they looked at it longer, between 4 and $6 \mathrm{sec}$, and in one case (a 23-month-old) it was observed for over 6 sec.

Differences were found in the use of tools between the drawing and coloring activities, although participants started both creative tasks without selecting a color or tool first (brush, marker, etc.), and those 23 months and younger did not intentionally use the color palette or any other tool at any time. During the drawing activity with the tablet only one boy ( 30 months) and one girl (33 months) used the color palette and they did so similarly, alternatively touching the colors and the white screen up to 9 times. On the other hand, changing the activity changed the results as well. All 7 of the children that used a tool at least once used the color palette to color the cat on the tablet, yet this varied according to age. A positive correlation (Pearson) $\left(p=.01, R^{2}=0.488\right)$ was seen between the child's age and the number of times they touched the color palette during the coloring activity (from 1 to 10 times), as well as the time that children spent playing on the coloring app (Pearson) $\left(\mathrm{p}=.01, \mathrm{R}^{2}=0.642\right)$, but not on the drawing app. For under $2 \mathrm{~s}$ the drawing app was more engaging, while older children showed more interest in the coloring app, as shown in Table 5.

\subsection{Coloring}

Nearly all of the 21 children initiated at least one interaction with the app for coloring, however only a third of the sample actually colored part of the outlined figure: 6 girls and one boy (from $24-35$ months old) intentionally colored part of the figure (the cat, mouse, or clouds).

Study participants under 24 months old did not color any figure or draw a purposeful shape or figure. This was also true for 2 of the 6 older children, specifically with one boy aged 30 months and one girl aged 32 months.

The data indicates that age does play a role in the number of lines that children can make along the same point when they are trying to color a picture. This number seems to increase in proportion with the child's age, (at 25 months a boy drew 9 lines and a girl 15 lines along the same point to color; two girls aged 26 and 27 months drew 20 and 24 lines and finally 3 older children -two girls and one boy- between 30 and 33 months drew between 30 and 40 lines when they colored a picture).

Although the small sample size (7 children) implies the need for further research, this increase coincides with creative development for this age range as detailed by Viktor Lowenfeld in his book "Creative and Mental Growth" (1947), although in this case the action is performed on an interactive digital device instead of paper. According to Lowenfeld, at this stage which he calls "scribble" (from 2 to 4 years old), children go from having rough control over their movements and little interest and capacity for coloring, resulting in little more than unorganized scribbles, to being able to fine tune their gestures and become more involved in coloring activities. In a similar manner, Piaget's theory of development holds that between 18 and 24 months a child begins to address problems through the use of mental representation, moving on from just trial and error.

\subsection{Analysis of apps for children}

Based on the results obtained from the first part of the study, the characteristics of the interaction design of a sample of drawing and/or coloring apps (coloring in drawings or painting with brushes or similar tools) explicitly targeted at users under 3 years old were analyzed. As previously mentioned, in this second phase a content analysis technique was employed using structured observation. The observation instrument included 5 variables related to the descriptive and thematic dimension of the app (i.e. its name and developer) and 20 dichotomous or continuous variables on the visual and interactive design (screen distribution, visual simplicity), consistency and user interface. A panel of experts validated the observation file and codebook and a pilot test was performed with 5 apps that were excluded from the final sample.

\subsubsection{Sampling}

The sample of drawing and coloring apps for tablets or smartphones, specifically aimed at children from the ages of 0,1 , or 2 years old, was chosen from 9 online databases. ${ }^{2}$ Also a search in the section "Apps + 4" (for all ages) was performed in the Apple Store using keywords (such as painting, finger-painting, drawing, coloring, etc., in English and Spanish) and separately confirming the age of the target group as listed on the developer's web page. All content recommended for children from the age of 3 years, "preschoolers", "young children", and "toddlers" was excluded given that those terms do not specifically refer to children under 3 years old (in one case the label "for toddlers" referred to children aged 3 and older). After the initial selection of apps that met those criteria, a further reduction was made to eliminate any that were redundant, that were from the same developer, or that had the same underlying visual and programming core, but with different objects or elements (e.g., princesses, cars, or animals to color). Apps

\footnotetext{
${ }^{2}$ The databases of apps were selected as part of a multilingual search (Spanish, English, Portuguese, Italian, and French) for sites that reviewed apps for children according to clear criteria and offering independent selection and categorization. See the following links to the websites: http://www. bestappsforkids.com/; https://www.commonsensemedia.org; http://www. mamamo.it/app; http://www.friendshipcircle.org/apps/; http://www. geekswithjuniors.com/; http://www.appspernens.cat/; http://www.applimini. com/; http://www.declickids.fr/ ; http://www.educationalappstore.com/
} 
Table 6

Number of taps the child must make before being able to start drawing/coloring. Zero signifies that the child can begin to paint without having to select any tool or having to tap on any screen or element prior to drawing/coloring.

\begin{tabular}{lll}
\hline $\begin{array}{l}\text { How many taps are required before being able to begin drawing/coloring? } \\
\mathrm{n}\end{array}$ & $\mathrm{f}$ \\
\hline $\mathbf{0}$ & 9 & $(28 \%)$ \\
1 & 7 & $(22 \%)$ \\
2 & 10 & $(31 \%)$ \\
3 & 5 & $(16 \%)$ \\
4 & 1 & $(3 \%)$ \\
\hline
\end{tabular}

were also excluded if drawing or coloring was only one available action and not the principle activity offered.

The final sample size was 32 apps $^{3}$ (18 for coloring, 9 for drawing, and 5 that offered both activities) from 29 developers, originating from 15 different countries.

\subsubsection{App review}

Even though children began interaction with a spontaneous touch of the screen without paying attention to options or tools, the great majority of apps require that a color or tool be selected first, with the need for at least one tap before beginning the activity of drawing or coloring. In $50 \%$ of the sample it was necessary to touch 2 or more screen elements (e.g. textual elements among the items to choose from, such as menus) before being able to start the creative activity, as shown in Table 6.

With reference to the number of screens that must be passed through before starting to draw or Paint (Table 7), in $85 \%$ of the cases there was more than one. Only 5 apps started with the drawing or painting screen ready to be used; two of them required a visual or audiovisual introduction that lasted only a few seconds and then disappeared to reveal the drawing screen.

One of the most relevant questions in the study involves the need to confirm which gestures the apps require children under 3 to make for drawing and coloring.

As seen in the following table, all of the apps require tapping (a quick touch of the screen) for drawing and coloring actions and in $91 \%$ the user must stroke with a finger to draw/color a line. One finding that stands out is that in 19 of the apps for children under 3 a flick (moving through elements or screens using a finger) was required to select colors or figures to color. This data contrasts with the results obtained when observing the gestures the children actually make. The drag gesture was necessary in 3 of the apps studied even though research indicates that children under 3 cannot successfully perform this action (Abdul-Aziz, 2013; Crescenzi et al., 2014; Nacher et al., 2015) Table 8.

Furthermore, apps were seen to have tools in different zones all along the perimeter of the screen, lacking a clear interaction design principle (Table 9). Even though children under 2 do not use them, all of the drawing and coloring apps had a color palette that was for the most part located along the lower edge of the screen.

This data suggests that developers of apps for children do not have a shared criteria for the interaction design of content for children even

\footnotetext{
${ }^{3}$ Amy's Coloring Book! - Color, Draw, Paint; Bubl Dessin; Color Me 2; Colorama - Kids Coloring Book; Coloring Book; Coloring book animals for preschool toddlers; CosmoCamp: Livre à colorier pour enfants d'âge préscolaire; Damki Town - Colouring Book; DipDap; Draw Kid - Drawing Pad for Kids - Kids Color \& Draw; Drawing; Drawing Den; Fun Coloring App; Glow Coloring; Gocco Zoo Pro - Creative Paint \& Play for Kids; Kid Art; Kids Coloring Book; Lazoo Art Box; Little Doodles; Live Colors for Kids; Memollow Coloring Pages for Kids; Mini LopArt; Miss Joséphine; Musical Paint; Ookii Squiggles by Baby First \& Lazoo; Paint My Wings; Paint Sparkles Draw - My First Coloring Book HD!; Sago Mini Bug Builder; Sago Mini; Doodlecast; Sago Mini Monsters; Tots Art; Zen Studio.
}

Table 7

Number of screens that a child must pass through before coming to the drawing/coloring screen. Zero indicates that the app opens onto the drawing/ coloring screen.

\begin{tabular}{lll}
\hline $\begin{array}{l}\text { How many screens must be passed through before starting to draw/color? } \\
\mathrm{n}\end{array}$ & $\mathrm{f}$ \\
\hline $\mathbf{0}$ & 5 & $(16 \%)$ \\
$\mathbf{1}$ & 5 & $(16 \%)$ \\
$\mathbf{2}$ & 2 & $(6 \%)$ \\
$\mathbf{3}$ & 11 & $(34 \%)$ \\
4 & 7 & $(22 \%)$ \\
5 & 2 & $(6 \%)$ \\
\hline
\end{tabular}

Table 8

Number of apps in which a specific gesture is required out of the total number of apps reviewed $(n=32)$.

\begin{tabular}{lll}
\hline Which gestures are required to play? & & \\
\hline Gestures & $\mathrm{f}$ & $\%$ \\
Tap & 32 & $(100 \%)$ \\
Stroke & 29 & $(91 \%)$ \\
Flick & 19 & $(59 \%)$ \\
Drag & 3 & $(9 \%)$ \\
Vertical scroll & 2 & $(6 \%)$ \\
Horizontal scroll & 1 & $(3 \%)$ \\
\hline
\end{tabular}

Table 9

Location of tools and color palettes on the drawing and painting screens. The frequency (and percentage) is out of the total number of apps reviewed $(\mathrm{n}=32)$.

\begin{tabular}{lll}
\hline & Tools f (\%) & Colors f (\%) \\
\hline No tools & $3(9 \%)$ & 0 \\
Lower-left corner & $3(9 \%)$ & $2(6 \%)$ \\
Lower-right corner & 0 & $2(6 \%)$ \\
Upper-left corner & $2(6 \%)$ & $1(3 \%)$ \\
Upper-right corner & $6(19 \%)$ & $1(3 \%)$ \\
Left side & $8(25 \%)$ & $6(19 \%)$ \\
Right side & $4(12 \%)$ & $4(13 \%)$ \\
Top & $7(22 \%)$ & $4(13 \%)$ \\
Bottom & $15(47 \%)$ & $17(53 \%)$ \\
\hline
\end{tabular}

though some of their choices may create obstacles to interacting well with their products.

The simplicity principle is also not always respected, on the contrary among the apps studied the presence of many elements on the screen was the norm. The number of available colors was greater than 20 in $38 \%$ of the cases (12 apps), in $34 \%$ there were 10 to 20 colors, and in only $25 \%$ ( 8 apps) did the palette include fewer than 6 colors. As outlined in previous studies, the number of available screen elements should be as low as possible (Crescenzi and Grané, 2016), as visual simplicity and simplicity of interaction are key CCI design principles. When these principles are ignored it may result in barriers to comprehension and game play.

Regardless of the type of content (colors, tools, etc.), the median number of interactive elements present on the game screen was 18 , although it was as high as 100 in some cases. The tendency to overload the screen with information and options was also seen on the start screen of the apps: there were between 3 and 60 simultaneously visible elements on the initial screens of the apps studied (the median number of interactive elements was 12). Again, the design issues with regard to visual simplicity are in fact an error that complicates the child's access to the resources available in the content, they are additional "noise" that impedes overall visual perception of the screen.

Of the more than 25 tools that were seen on the game screens, the most common are summarized in Table 10. It is surprising that a user under 3 years old is presumed to know beforehand what type of line a 
Table 10

Frequencies (and percentages) of the tools that are shown on the screen of the drawing and coloring apps for children under 3 years old, out of the total number of apps reviewed $(\mathrm{n}=32)$.

\begin{tabular}{lll}
\hline Tools & On Screen & Under "Properties" \\
\hline Marker & $17(53 \%)$ & - \\
Eraser & $14(44 \%)$ & 3 \\
Brush & $14(44 \%)$ & 7 \\
Screen Capture & $12(38 \%)$ & - \\
Stickers & $10(31 \%)$ & - \\
Paint Pot & $9(28 \%)$ & 1 \\
Magnifying Glass/Zoom & $4(13 \%)$ & - \\
Airbrush & $3(9 \%)$ & \\
\hline
\end{tabular}

brush, a pot of paint, a marker, or even an airbrush will make, recognize the icon for each of them, and then choose them for those specific properties (in the case of the brush, eraser, and pot of paint). There would appear to be a lack of knowledge on the part of the designers and producers with regard to the abilities of children under 3 , their abilities, processes and the discovery of their surroundings that shapes their mental models (Luquet, 1927). This violates one of the most relevant principles in usability and interaction design for ensuring the functionality of applications: being familiar with the mental models and cultural referents of the end-user (Luquet, 1927; Norman 1990; Grané and Crescenzi, 2016), in this case children under 3 years old.

With reference to the coloring activity, of the 23 apps with this function that were studied, only 11 auto-filled with color when they were touched (or at least this was an additional option apart from painting with individual strokes). This is a useful strategy that would allow younger children who are still developing fine motor skills to use the app.

In the sample selection, a single figure was most often presented for coloring in the center of the screen (15 apps), although in 5 cases other scenery or background elements were also present (distributed in at least one case in every one of the 9 zones of the screen as indicated in Figs. 4 and 5) and in 3 apps there was a set of elements to color, without a main figure. The placement of figures in the center of the screen corresponds to the drawing and painting seen in the participants, although in 8 of the apps the use of diverse elements in the same screen did not support the visual perception of the central figure for the child.

\section{Discussion}

The 21 children participating in the study began their spontaneous interaction with the two apps (RQ1) by touching the central zone of the screen with their index fingers, although there were some exceptions (use of their thumbs, middle finger, or both hands). This points to the possibility of including multi-touch functionality to apps designed for children under 3 years old, regardless of their content, given the number of touch types required to interact with the screen. This recommendation is not meant to contradict the advice of Vatavu and other researchers (2015) to avoid the inclusion of multi-touch requirements (such multi-touch as drag and drop) in the interaction design of content for young children, it is instead meant to include the functionality in a complementary manner, in recognition of the evolution of gestures as an essential aspect to take into consideration in the development of apps and the need to simplify the design by adapting it to the age of the target user.

Study participants between 14 and 33 months old appear to adapt their gestures to the content of the app, making the first touch for coloring a stroke in most cases (89.5\%) and less often a tap; while the observation of gestures used to begin drawing showed one out of three children used a tap and three children began with a press (RQ3). The frequent use of a stroke, and to a lesser extent a press, correlates with the results of previous studies (summarized in Table 1). Still, two results that differ from what was seen in previous studies stand out: on the one hand the results of the study did not show a predominate use of tapping in children under 3 years old; on the other hand less variety of gestures were seen during the spontaneous interactions (only three types were seen: stroke, tap, and press). An explanation for both results may lie in the activities presented in both studies. The two apps used in the initial study focus on drawing and coloring, and the interaction is not focused on the selection of elements or objects on the screen as often occurs in other apps for children; in addition, the gesture in this research is not conditioned by instructions or examples as in other studies (where a gesture is made following instructions or cues).

The differences between the gestures that the children made when beginning the two activities suggest that children from 14 months begin to adapt their gestures to the content as early as 3 years old, on the condition that the content is familiar based on previous knowledge (e.g., experience finger-painting on paper). This was the anticipated result and aligns with the parent surveys and the theories of development (Marsh et al., 2015; Wen and Zainon, 2015). However, as far as the researchers are aware this is the first observational study of children under 24 months old interacting spontaneously with an interactive screen and thus contributes relevant empirical data to the debate on the design and use of apps for children under 2 years old. The actions and gestures observed are not uniform among the participants, instead they develop in relation to the child's age (RQ2) which is consistent with previous studies (Marsh et al., 2015; Cristia and Seidl, 2015; Vatavu, Cramariuc and Schipor, 2015; Abdul-Aziz, 2013). The data indicate that there is a progression with coloring and that the number of consecutive strokes made while coloring the same area of a figure increases with age. With reference to the use of available tools in the two apps featured in the study, it was only from the age of 24 months that researchers began to see examples of intentional use of the color palette or other tools (RQ4). While children 24 months and older began to use the color palette intentionally, only two of them used the brush and the eraser, and in only a single case were they used more than once. These results concur with those of Abdul-Aziz (2013) on the differences between children under 3 using touch screens and those over 3 years old, even though the sample group in this study only included 6 subjects between 24 and 35 months that colored intentionally, a number that is insufficient for drawing a clear conclusion in this regard and more studies will be needed to confirm this finding. Nevertheless, the results appear to indicate that the presences of tools in drawing and coloring apps directed at children under 3 years old is redundant and in some cases may even be an obstacle to completing the task (e.g., researchers observed one child's drawing activity interrupted by the accidental selection of the eraser). This result contrasts with the wide array of tools and the variety of colors (generally more than 20 ) that were seen in the 32 creativity apps in the sample selection for the second part of the study. Although some design options such as visual and interactive simplicity were considered in the 32 apps chosen for the sample, the designers did not appear to have taken into account the need for multitouch functionality, visual design (the number of elements on the screen or their distribution), and the user's previous knowledge or lack thereof (e.g., the different lines made by a brush, marker, or airbrush). The results of the content analysis undertaken in this study point to the designers' lack of knowledge regarding mental models for users under 3 years old. A consideration of the development of fine motor skills was also absent in the interaction design elements, as was the case with the gestures required for interacting with the children's apps reviewed (RQ5), which is in line with the conclusion of previous studies about touchscreen use by children and adults with motor impairments (Anthony et al., 2013). Although the developers indicate that the apps in the sample are appropriate for children from the age of 0,1 , or 2 years old, they are not designed for children under 3 . 


\section{Conclusions}

Presented here are the principle findings intended to contribute to the design and development of appropriate creativity apps for children under 3 years old, reached after two phases of investigation. They relate to both the interaction of children under 3 with two specific creativity apps, as well as the suitability of a larger sample of the same type of application for their target users.

The observation of the interaction of children under 3 with creative apps suggests that digital resources for these ages require a design focused on visual simplicity, where the center of the screen contains the essential visual information and the number of active elements is reduced.

However, precautions must be taken in terms of the generalization of the findings to other contexts and environments since the number of subjects is relatively low ( 21 children). A threat to validity of the study is that it was not possible to clearly establish the influence of the participants' tablet use at home through the parent questionnaire, due to the potential for a socially desirable responding bias and non-responder bias. Those biases should be reduced in future research by employing an interview instead of a self-administered questionnaire.

Apart from that, the results are only applicable to drawing and painting applications, as these types of activities may impact the gestures that children perform (for example, drawing and coloring apps invite children to perform mostly stroke and tap gestures and not scroll).

The first research issue to highlight is that $72 \%$ of the creative apps reviewed required between 1 and 4 taps before being able to start drawing/coloring, but no participant started the task by selecting a color or tool. Instead, every child just began painting. As such, the option for creativity apps to open onto the drawing/coloring screen without having to select a tool prior to painting would appear to be the most appropriate default setting for users under 3-40\% of whom use the apps without parental supervision and $25 \%$ owning their own tablet, according to Marsh et al. (2015).

Creative applications directed at children under 3 should support multi-touch interaction because of the variety of touches and gestures that are used for drawing or coloring (experimenting with their index, thumb or middle finger, or more than one finger, occasionally employing both hands, alternating or at the same time).

Results suggest that applications for under $2 \mathrm{~s}$ should not include tools (color palette, brushes, erases, etc.) considering that participants under 23 months (14 children, the $67 \%$ of the sample) did not intentionally use tools at any time. Apps for under $3 \mathrm{~s}$ could include a few tools (e.g., a color palette with 3-4 colors and a brush) although this is not essential for the use of creative apps. In fact, only 5 children between 23 and 33 months deliberately used the color palette more than once during the creative activities and only one employed the other tools. The 32 apps analyzed presented an average of 18 interactive elements (colors and tools) on the game screen and the number of available colors was more than 6 in $75 \%$ of the apps.

Placing tools in the lower portion of the touch screen may result in children selecting different options involuntarily with their hand or arm while drawing or coloring. Due to the accidental use of zone $\mathrm{G}$ (the location of the tools in the test app) and the resulting interference in the creative process, this area does not seem to be a good place for displaying the tools. No children started the spontaneous coloring or drawing activity in zone B, so this may be a better option for placing tools in this type of app. Nevertheless, confirmation of these findings will require more study to examine the effects of different kinds of apps on young children's touch based interactions.

Study participants under 24 months old as well as some older children did not color any figure or draw a purposeful shape or figure even after spending up a minute interacting with the app and half of them $(5 / 10)$ changed their gestures according to the content only through the use of the stroke gesture. From 24 months old, the coloring app appears to have been more engaging than the drawing app.

The stages of child development determine the observable behavior and capacity that children have for interacting with machines, establishing the options for movement, the handling of physical objects, speed, precision, etc., and from the point of view of CCI there is a need to clarify how changes in fine motor skills affect children's interactions with touch screens at different ages. Although it is hoped that these results contribute to a better understanding of the interaction of children under 3 years old with this technology, further investigation on spontaneous interactions will be needed in order to improve the design of tactile interfaces directed at this age group Table 8.

\section{Acknowledgments}

The research would not have been possible without the kindergarten teachers and parents as well as the young participants in London and Barcelona. I also want to thank the colleagues from the London Knowledge Lab and our collaborator Marta López.

\section{References}

Abdul-Aziz, N.A.B., 2013. Children's interaction with tablet applications: gestures and interface design. Int. J. Comput. Inf. Technol. 02 (03), 447-450 May 2013.

Ackermann, E., 1991. The agency model of transactions: towards an understanding of children's theory of control. In: Montangero, J., Tryphon, A. (Eds.), Psychologie Génétique et Sciences Cognitives. Fondation Archives Jean Piaget, pp. 63-73 1991.1.

Ahearne, C., Dilworth, S., Rollings, R., Livingstone, V., Murray, D., 2015. Touch-screen technology usage in toddler. Arch. Dis. Child. 2015/12, 181-183. https://doi.org/10 1136/archdischild-2015-309278.

Anthony, L., Kim, Y., Findlater, L., 2013. Analyzing user-generated youtube videos to understand touchscreen use by people with motor impairments. In: Proceedings of the SIGCHI Conference on Human Factors in Computing Systems. ACM, pp. 1223-1232.

American Academy of Pediatrics, Committee on Public Education, 1999. Media education. Pediatrics 104, 341-343. https://doi.org/10.1542/peds.2010-1636.

American Academy of Pediatrics, Council on Communications and Media, 2011. Media use by children younger than 2 years. Pediatrics 128, 1040-1045. https://doi.org/10. 1542/peds.2011-1753.

Börjesson, P., Barendregt, W., Eriksson, E., Torgersson, O., 2015. Designing technology for and with developmentally diverse children - a systematic literature review. In: IDC 2015. Medford, MA, USA.

Bruckman, A., Brandlow, A., Forte, A., 2009. HCI for kids. In: Sears, A., Jacko, J.A. (Eds.), Human-computer interaction. Designing for Diverse Users and Domains. CRC Press Taylor \& Francis Group, Boca Raton, FL, pp. 33-50.

Butler, J., Holden, K., Lidwell, W., 2003. Universal Principles of Design: A CrossDisciplinary Reference. Rockport Publishers, Gloucester, MA.

Clements, D.H., Sarama, J., 2003. Young children and technology: what does the research say. Young Child. 58 (6), 34-40.

Couse, L.J., Chen, D.W., 2010. A tablet computer for young children? Exploring its viability for early childhood education. J. Res. Technol. Educ. Int. Soc. Technol. Educ. 43 (1), 75-98.

Crescenzi, L., 2013. Como recoger datos audiovisuales en la investigación de campo con niños muy pequeños. Digit. Educ. Rev. (24), 43-52.

Crescenzi, L., Jewitt, C., Price, S., 2014. The role of touch in preschool children's learning using iPad versus paper interaction. Aust. J. Lang. Lit. 37 (2), 86-95.

Crescenzi, L., Grané, M., 2016. Análisis del diseño interactivo de las mejores apps educativas para niños de cero a ocho años. / An analysis of the interaction design of the best educational apps for children aged zero to eight. Comunicar Vol.46, 77-85. http://dx.doi.org/10.3916/C46-2016-08.

Cristia, A., Seidl, A., 2015. Parental reports on touch screen use in early childhood. PLoS One 10 (6), e0128338. https://doi.org/10.1371/journal.pone.0128338.

Dondis, D.A., 1974. A Primer of Visual Literacy. MIT Press, Cambridge, Mass. USA.

Druin, A., Solomon, C., 1996. Designing Multimedia Environments For Children. John Wiley and Sons Ltd, New York.

Dumas, J.S., Redish, J.C., 1993. A Practical Guide to Usability Testing. Ablex, Norwood, NJ.

Flewitt, R., Kucirkova, R., Messer, D., 2014. Touching the virtual, touching the real: iPads and enabling literacy for students experiencing disability. Aust. J. Lang. Lit. 37 (2), $107-116$.

Goldstein, N., 1997. Design and Composition, (10th edition). Pearson Education, Upper Saddle River, United States.

Goodwin, K., Highfield, K., 2012. iTouch and iLearn: an examination of 'educational' apps. In: Early Education and Technology for Children conference, March 14-16, 2012. Salt Lake City, Utah.

Grané, M., Crescenzi, L., 2016. Modelo teórico para el diseño y evaluación de la calidad en las apps infantiles (0-8 años). Digital Education Review 29, 227-245. http:// revistes.ub.edu/index.php/der/article/view/14497/pdf ISSN 2013-9144.

Greenfield, P., Beagles-Roos, J., 1988. Radio vs. television: their cognitive impact on children of different socioeconomic and ethnic groups. J. Commun. 38 (2), 71-92. 
Guernsey, L., 2013. Screen Time: How Electronic Media - From Baby Videos to Educational Software - Affects Your Young Child. Basic Books, New York.

Hanna, L., Risden, K., Alexander, K.,J., 1997. Guidelines for usability testing with children. Interactions 1997 (5), 9-14.

Hiniker, A., Sobel, K., Hong, S.R., Suh, H., Irish, I., Kim, D., Kientz, J.A., 2015. Touchscreen prompts for preschoolers: designing developmentally appropriate techniques for teaching young children to perform gestures. In: IDC 2015. Medford, MA, USA.

Hourcade, J.P., 2008. Interaction design and children. Human-Computer Interaction 1 (4), 277-392 (2007).

Kirkorian, HK., Wartella, EA., Anderson, DR., 2008. Media and young children's learning. Future Child. 18 (1), 39-61.

Kirkorian, H.L., Pempek, T.A., 2013. Toddlers and touch screens: potential for early learning? Zero to Three 4 (33), 32-37 March 2013.

Lauricella, A.R., Pempek, T.A., Barr, R., Calvert, S.L., 2010. Contingent computer interactions for young children's object retrieval success. J. Appl. Dev. Psychol. 31 (5), 362-369. https://doi.org/10.1016/j.appdev.2010.06.002

Lowenfeld, V., 1947. Creative and Mental Growth. Macmillan, New York.

Luquet, G.H., 1927. Le Dessin enfantin. Félix Alcan, Paris.

Marsh, J., Plowman, L., Yamada-Rice, D., Bishop, J.C., Lahmar, J., Scott, F., Davenport, A., Davis, S., French, K., Piras, M., Thornhill, S., Robinson, P., Winter, P., 2015. Exploring play and creativity in pre-schoolers' use of apps: Final project report. Technology and Play. Technology and Play Retrieved from. http://www. techandplay.org/reports/TAP_Final_Report.pdf.

McKnight, L., Fitton, D., 2010. Touch-screen technology for children: giving the right instructions and getting the right responses. In: IDC 2010. Barcelona, Spain. June 9-12, 2010.

Nacher, V., Jaen, J., Catala, A., 2014. Exploring visual cues for intuitive communicability of touch gestures to pre-kindergarten children. In: Conference: ACM International Conference on Interactive Tabletops and Surfaces. At Dresden. 2014.

Nacher, V., Jaen, J., Navarro, E., Catala, A., González, P., 2015. Multi-touch gestures for pre-kindergarten children. Int. J. Hum. Comput. Stud. 73, 37-51.

Nielsen, J., Molich, R., 1990. Heuristic evaluation of user interfaces. In: Proc. ACM CHI'90 Conf. Seattle, WA. pp. 249-256 1-5 April.

Norman, 2003. Emotional Design: Why we Love (or hate) Everyday Things. Basic Books, New York.

Norman, D., 1990. Why interfaces don't work. In: Laurel, B. (Ed.), The Art of Human Computer Interface Design. Addison Wesley, Massachusetts, pp. 209-219.

Read, J.C., Bekker, M., 2011. The nature of child computer interaction. In: BCS-HCI '11 Proceedings of the 25th BCS Conference on Human-Computer Interaction. Newcastle, United Kingdom. pp. 163-170 July 04-08.

Read, J.C., Markopoulos, P., 2013. Child-computer interaction. International Journal of Child-Computer Interaction 1 (1), 2-6. https://doi.org/10.1016/j.ijcci.2012.09.001. ISSN 2212-8689.

Resnick, M., 1991. MultiLogo: a study of children and concurrent programming. Interactive Learning Environments 1 (3), 158-170.

Rideout, V., 2011. Zero to eight. Children's media use in America. Common Sense Media, San Francisco Accessed at. www.commonsensemedia.org/sites/default/files/ research/zerotoeightfinal2011.pdf.

Rockman, et al., 2010. PBS Kids iPod app study: Findings and outcomes. Study Commissioned by PBS Kids. Public Broadcasting Service (U.S.). http://cl.ly/ 1k1K1n0f3I0M1E3o1L2L.

Schmidt, ME., Pempek, TA., Kirkorian, HK., Lund, AF., Anderson, DR., 2008. The effects of background television on the toy play behavior of very young children. Child Dev.
79 (4), 1137-1151

Shuler, C., 2009. iLearn; A content Analysis of the Itunes App Store Education Section 2009 The Joan Ganz Cooney Center at Sesame Workshop, New York.

Troseth, G., Russo, C., Strouse, G., 2016. What's next for research on young children's interactive media. Journal of Children and Media 10 (1), 54-62. https://doi.org/10 1080/17482798.2015.1123166.

Vatavu, R.D., Cramariuc, G., Schipor, D.M., 2015. Touch interaction for children aged 3 to 6 years: experimental findings and relationship to motor skills. Int. J. Hum. Comput. Stud. 74, 54-76.

Vernadakis, N., Avgerinos, A., Tsitskari, E., Zachopoulou, E., 2005. The use of computerassisted instruction in preschool education: making teaching meaningful. Early Child. Educ. J. 33 (2), 99-104.

Watlington, D., 2011. Using iPod Touch and iPad Educational Apps in the classroom. In: Koehler, M., Mishra, P. (Eds.), Proceedings of Society for Information Technology \& Teacher Education International Conference 2011. Association for the Advancement of Computing in Education (AACE), Chesapeake, VA, pp. 3112-3114.

Wen, YH., Zainon, WMNW., 2015. Understanding the human-computer interface requirements in developing applications for children. Inf. Knowl. Manag. Vol.5 (3).

Yee, C.K., Ling, C.S., Yee, W.S., Zainon, W.M., 2012. GUI design based on cognitive psychology: theoretical, empirical and practical approaches. In: Computing Technology and Information Management (ICCM), 2012 8th International Conference on. 2. IEEE, pp. 836-841.

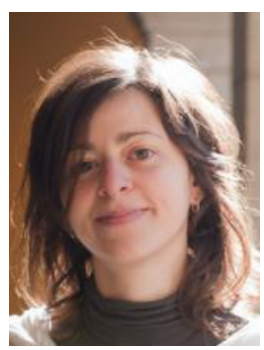

Lucrezia, Crescenzi Lanna https://www.researchgate. net/profile/Lucrezia_Crescenzi is a developmental psychologist with an interest in media research with and for children; she is a postdoc researcher in the Interactive Media Lab at the University of Vic (UVIC-UCC).

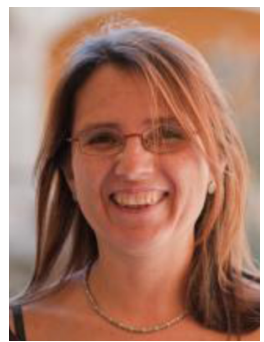

Mariona, Grané Oro http://www.lmi.ub.edu/personal/ mariona/ holds a $\mathrm{PhD}$ in Educational Sciences from the University of Barcelona and is interested in the interaction design of educational environments and resources; she is a postdoc researcher in the Interactive Media Lab at the University of Barcelona. 